\title{
Review: adding antileucotrienes to inhaled corticosteroids reduces exacerbations in symptomatic chronic asthma
}

\author{
Ducharme F, Hicks G, Kakuma R. Addition of anti-leukotriene agents to inhaled corticosteroids for chronic asthma. \\ Cochrane Database Syst Rev 2002;(1):CD003133 (latest version 25 Oct 2001).

\section{QUESTION: In patients with chronic asthma, how effective and safe is daily antileucotriene $(A L)$ treatment plus inhaled corticosteroids (ICS) compared with ICS alone?}

Source of funding: in part, Canadian

Cochrane Network

For correspondence: $\mathrm{Dr}$ University, Montreal,

Ouebec, Canada.

Francine.ducharme@ muhc.mcgill.ca. F M Ducharme, McGill

\section{Data sources}

Studies were identified by searching 4 electronic databases up to September 2001; scanning the reference lists of articles and reviews; reviewing meeting abstracts (1998 to 2000); and contacting the international headquarters of AL manufacturers.

Antileukotriene (AL) agents (higher-than-licensed dose) plus inhaled corticosteroids (ICS) v ICS alone for symptomatic chronic asthma at 4 to 16 weeks*

\begin{tabular}{|c|c|c|c|c|}
\hline Outcome & $A L+I C S$ & ICS & RRR $(95 \%$ Cl) & NNT (Cl) \\
\hline Exacerbations & $2 \%$ & $7 \%$ & $66 \%(12$ to 87$)$ & 22 (12 to 125$)$ \\
\hline
\end{tabular}

\section{COMMENTARY}

AL agents provide the first new treatment option in asthma for some time. ALs might be helpful as alternatives to ICS in patients starting regular treatment and as an addition to ICS.

The review by Ducharme $e t$ al deals with the latter, when control is inadequate with ICS or as a method of reducing the ICS dose. The reported results are disappointing. In short term studies, exacerbations were reduced and control was slightly improved with the addition of AL, but some doses were greater than current licences allow. No difference existed between adding AL to ICS and doubling the dose of ICS, although steroids have been found to have a rather flat dose response, and the introduction of AL did not allow for a reduction in ICS dose in these studies.

2 large studies ${ }^{12}$ have examined the effects of adding long acting inhaled $\beta$ agonists (LABAs) at the same point and have shown that LABAs add to the benefits of ICS and are more effective than doubling the steroid dose. LABAs also reduce exacerbations. ${ }^{1}$ In the studies reviewed by Ducharme $e t a l$, patients were not taking LABAs. The clinical implications would seem to be that LABAs should be the first option for patients who are not well controlled with ICS or who require high doses for control. AL might be considered after assessing the response in each patient.

The use of AL as a first prophylactic agent has been assessed in a Cochrane review. ${ }^{3}$ AL agents were inferior to ICS for effects on lung function, symptoms, and quality of life, although again they were not statistically different for exacerbations.

New drugs for asthma must contend with the fact that ICSs are very effective in asthma and have few side effects at usual doses. AL agents, at the higher doses seen in this review, were found to affect liver function tests, but they are generally safe drugs in asthma; however, their effectiveness is limited and indications for their use have not been broadened by this review.

$$
\begin{array}{r}
\text { P John Rees, MD } \\
\text { Guy's, King's and St Thomas's School of Medicine } \\
\text { London, UK }
\end{array}
$$

1 Pauwels RA, Lofdahl CG, Postma DS, et al. Effect of inhaled formoterol and budesonide on exacerbations of asthma. $N$ Engl J Med 1997;337:1405-11.

2 Greening AP, Ind PW, Northfield M, et al. Added salmeterol versus higher-dose corticosteroid in asthma patients with symptoms on existing inhaled corticosteroid. Lancet 1994;344:219-24.

3 Ducharme FM, Hicks GC. Anti-leukotriene agents compared to inhaled corticosteroids in the management of recurrent and/or chronic asthma. Cochrane Database Syst Rev 2000;(3):CD002314.

\section{Study selection}

Studies were selected if they were randomised controlled trials evaluating the effectiveness of AL for $\geqslant 1$ month in patients with asthma who were $\geqslant 2$ years of age.

\section{Data extraction}

Data were extracted independently by 2 reviewers on study quality, patient characteristics, intervention type and duration, and main outcome measures.

\section{Main results}

13 trials (12 in adults and 1 in children) were included. Combining data from 2 of the 6 trials in symptomatic patients and after 4 to 16 weeks of treatment showed that the addition of higher-than-licensed AL doses to ICS reduced the risk for exacerbations requiring systemic corticosteroids (table). The addition of higherthan-licensed doses also led to an improvement in $\mathrm{FEV}_{\text {, }}$ (weighted mean difference [WMD] 0.10 litre, 95\% CI 0.01 to 0.20 ), peak expiratory flow rate (WMD 27.2 $\mathrm{l} / \mathrm{min}$, CI 18.6 to 35.8$)$, asthma symptom scores (standardised mean difference [SMD] -0.46 , CI -0.25 to -0.66 ), and mean use of $\beta_{2}$ agonists (SMD -0.43 puffs $/ \mathrm{d}$, CI -0.22 to -0.63$)$. The groups did not differ for any other outcomes. The addition of licensed doses led to non-statistically significant reductions in the risk for exacerbations requiring systemic steroids (relative risk reduction $39 \%$, CI $-5 \%$ to $64 \%$ ).

2 trials that compared ICS plus AL at higher-thanlicensed doses with double dose ICS in symptomatic patients showed no differences between groups for the number of exacerbations requiring systemic steroids or for any other outcome.

4 trials that compared AL (at licensed doses) plus ICS with the same dose of ICS in well controlled patients showed no difference in reduction in ICS dose after 12 to 20 weeks and no difference in the lowest tolerated dose of ICS.

\section{Conclusions}

In patients with chronic asthma who are symptomatic while receiving moderate to high doses of inhaled beclomethasone, the addition of 2 to 4 times the licensed dose of antileucotriene agents reduces the rate of exacerbations that require systemic corticosteroids. Insufficient evidence exists that antileucotriene confers benefit over doubling the dose of corticosteroids or that it has an inhaled corticosteroid-sparing effect. 